\title{
Application of physical and energetic approach to estimation and selection of atmospheric protection systems for energetic devices
}

\author{
Ekaterina Lysova $^{1 *}$, Oksana Paramonova ${ }^{1}$, Natalia Samarskaya ${ }^{1}$, Oksana Gyrova ${ }^{1}$, and \\ Irina Tsarevskaya ${ }^{1}$ \\ ${ }^{1}$ Don State Technical University, 344022, Sotsialisticheskaya str. 162, Rostov-on-Don, Russia
}

\begin{abstract}
The air basin of cities is subjected to considerable pollution, including waste gases generated during the production of thermal and electric energy by power plants. However, power plants are an indispensable element of the life support system on urban areas and they can not be taken out of the city, that means minimizing losses, both material and energy. Therefore, the problem of the correct choice of structural elements and operating characteristics of the process and a system for reducing air pollution is becoming very important. The paper analyzes the most well-known and practical scientific approaches to the selection of optimal measures to reduce air pollution, their advantages and disadvantages are revealed. The authors have singled out the physical and energetic approach as the most acceptable one. The approach is based on the theory of dispersed systems stability, the analysis of the main provisions which allowed us to systematize the parameters of properties, energy parameters and stability of gaseous pollutants formed during the operation of power plants and to construct a scheme for the transformation of gaseous pollutants for the process of reducing air pollution has been performed. At the same time, stability is the resultant criterion characterizing the gaseous pollutants behavior.
\end{abstract}

\section{Introduction}

The development of mankind is impossible without the widespread use of electrical and thermal energy and is characterized by annual increase of energy resources consumption. This, in turn, leads to an increase in pollution of the environmental components, primarily atmospheric air. Consequently, the environmental safety of technological processes for heat and electric energy output ensuring is a priority for the state and society.

The works of many scientists, such as Belik S.E., Bespalov V.I., Boguslavskiy E.I., Valdberg A.Yu., Gibbs V., Gluzberg V.E., Greene X., Zhuravlev V.P., Ishchuk I.G., Kouzov P.A., Lane V., Livchak I.F., Logachev I.N., Minko V.A., Mishner Y., PetryanovSokolov I.V., Rehbinder P.A., Rekun V.V., Rusanov A.A., Saranchuk V.I., Segal I. Ya., Sidorenko V.F., Sou S., Spurny To., Sutugin A.G., Uzhov V.N., Fuchs N.A., Shtokman

* Corresponding author: katerina.lysova0803@gmail.com 
E.A., Strauss W. and other authors [1-6], are devoted to study and assessment of the negative impact of stationary and mobile power plants on the components of the environment, study of the polluting aerosol as a dispersed system, its behavior under external conditions, studies of the problems related to cleaning and dispersion, as well as the improvement of technique and purification technology and also forced air dispersion.

To control the polluting aerosols behavior, it is important to know the processes and phenomena occurring in them. The use of the theory of disperse systems allows us to give the most complete characterization, to systematize parameters of properties by groups, the main classification criterion in which is the physical essence of processes and phenomena occurring in aerosols [7, 8]. This approach, even at the design stage of the air pollution reduction system, makes it possible to make the right choice of the structural elements and operating characteristics of the process as well as the purification system and, if necessary, the forced dispersion of the exhaust gases.

Thus, the relevance of research aimed at studying and systematizing the properties of polluting aerosols as disperse systems for the purpose of controlling their parameters that affect the efficiency of purification and forced dispersal of waste gases from power plants is obvious.

\section{Methods}

Methods of examination are based on the main statements of the theory of dispersion systems, system analysis, analytical generalization of the known scientific and practical results.

\section{Results}

The need for energy conversion is associated with the need to use certain types of energy, mainly heat and electricity in technological processes. These two types of energy are used in various forms: heat is used in the form of steam, heated at different temperatures gases and water, electric energy is used in the form of alternating or direct current and at different voltage levels.

At present, combined generation of heat and electric energy in Russia is made practically only at steam turbine thermal power plants, which provide only $36 \%$ of thermal energy, since the use of such TPP is possible only in the largest cities where there is a sufficient density of thermal loads. The bulk of thermal energy $(46 \%)$ is produced in boiler houses, which not only do not produce electricity, but also are its largest consumers in the sphere of housing services and utilities.

The most common sources for generating thermal and electric energy are organic fuels [9]. In the structure of consumption of various types of organic fuels, natural gas predominates $(73,0 \%)$ and coal $(11,3 \%)$, as well as fuel oil, which is often used as a reserve fuel (Fig. 1).

The production of thermal and electric energy is accompanied by significant material and energy pollution of the environment $[10-14,15]$.

When operating power plants, it is the atmospheric air that is subjected to maximum anthropogenic load.

In our opinion, the most significant pollutants from the environmental point of view that enter the air basin of cities from power plants are gaseous substances (oxides of nitrogen 


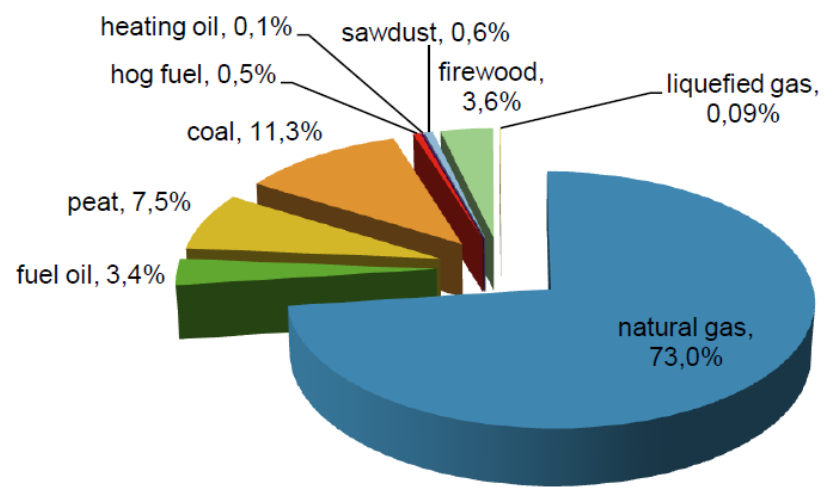

Fig. 1. Structure of various types of organic fuel consumption by boiler houses in Russia.

and carbon produced by the combustion of all types of organic fuel, sulfur dioxide released by the combustion of solid and liquid organic fuels). These substances give the maximum contribution to the pollution of the air basin and are formed by burning almost any type of fuel. In addition, they are susceptible to various changes in the air basin, for example, the capture of clouds and fogs by drops, followed by their washing out by sediments, entry into chemical reactions with other pollutants with the formation of more toxic substances [16, 17].

The solution of the atmospheric air pollution problem by power plants is possible due to the implementation of various measures, as well as methods, means and technical units. This, in turn, causes the problem of choosing the final solutions for air purification from toxic components.

The study of existing methods of assessment and selection of optimal measures to reduce air pollution by urban facilities, including power plants, suggests that currently the main criteria in such methods are indicators of environmental and economic efficiency. However, usage of these two criteria as optimization ones does not always make it possible to uniquely choose technical solutions to reduce air pollution.

Among the most known and practical scientific approaches to the selection of optimal measures to reduce air pollution in urban facilities, including power plants, the following factors are included:

- the theory of solutions to reduce atmospheric pollution [18];

- quantitative method of normalizing pollutants in the air basin [19];

- a thermodynamic method for estimating methods for reducing harmful emissions (exergic analysis) $[20,21]$;

- physical and energetic approach [22, 23].

The theory of solution to reduce atmospheric pollution, as described in [18], includes the assessment and selection of the best options for solutions to reduce environmental pollution in urban areas. The basis of the approach is the matrix optimization of the sequence of choice of organizational and technical solutions for specific production and technological conditions, allowing to make such decisions that would be adapted to the conditions under consideration and will meet the specified requirements. In the authors' opinion, the universality of the approach [18] is provided by the algorithmic construction principle, while the openness of the algorithm of the selection procedure makes it possible to make changes and additions to it, providing further development of the methodology. However, the presence of a large amount of source information, intermediate and resulting parameters, are significant drawbacks of the proposed approach.

The quantitative method of normalizing pollutants in the air basin [19] assumes the use of the maximum permissible emission limit as the main criterion for estimating and 
selecting the optimal purification technology so as to comply with the condition of nonexceeding of the actual concentration of pollutants on the border of the sanitary protection zone over the maximum allowable concentration. The drawback of this methodology, based on the use of indicators of maximum permissible levels of human impact on the environment, is the lack of commonality in assessing the impact on all components of the environment at the same time (atmosphere, lithosphere, hydrosphere), as well as its focus on human protection from this impact only, not the entire environment.

In the opinion of the authors of the thermodynamic method for estimating methods for reducing harmful emissions (exergic analysis) [20,21], the exergy of the energy and substance flows discharged into it is the fundamental index characterizing the total impact of any objects of anthropogenic activity on the environment. With regard to the release of pollutants with waste gases, it becomes evident that the smaller the exergy value is, the more environmentally friendly is the production unit the emission stream has, so the less is the «load» on the environment in the form of thermal and chemical pollution.

The main disadvantages of the considered methodological approaches to the assessment and selection of the optimal technology for cleaning urban facilities including boiler houses are:

- the lack of consideration of useful and expended energy during the process of air purification from pollutants;

- the requirement for a preliminary selection of equipment for air purification from pollutants;

- lack of consideration of the pollutants properties in determining the actual and required purification efficiency.

From our point of view, the most perfect is the physical and energetic approach [22, 23], within the framework of which a comprehensive methodology for selecting and forming highly efficient and economical air purification systems is presented. Advantages of the complex methodology of selection and formation of highly efficient and economical air purification systems within the framework of the physical and energetic approach $[22,23]$ are:

- possibility of adjusting the methodology as new theoretical and practical knowledge is accumulated;

- possibility of conducting a comparative analysis of the «method - way of implementation

- technological implementation» combinations to achieve the required concentrations of pollutants in the air;

- optimization of the air pollution reducing process while creating new, more sophisticated structural elements of anti-pollutant systems;

- accounting of real industrial and technological conditions at enterprises;

- the construction of complex anti-pollutant substances systems, including simpler ones.

Despite the lack of a comprehensive methodology for selecting and forming highly efficient and economical air purification systems (the absence of a functional element transporting pollutants in the anti-pollutant system) this is the one that is most suitable for selecting technologies and optimizing the operating parameters of the waste gas cleaning processes of power plants.

Each of the gaseous pollutants formed during the operation of power plants can be considered from the position of the disperse systems theory and characterized by a specific set of properties parameters. In this case, the dispersion medium (D.M.) is represented by air, and the dispersed phase (D.P.) is gaseous pollutants. It is known [6, 24], that parameters of aerosol properties (aerosol) can be divided into 3 groups (Fig. 2):

1 -st group - parameters of the first kind - properties parameters of the pollutants $\mathrm{PP}_{\mathrm{A}}$, which are a set of parameters of the dispersion phase property (D.P.) PP $P_{\text {D.P. and the }}$ dispersion medium (D.M.) PP $P_{\text {D.M. of this substance; }}$ 


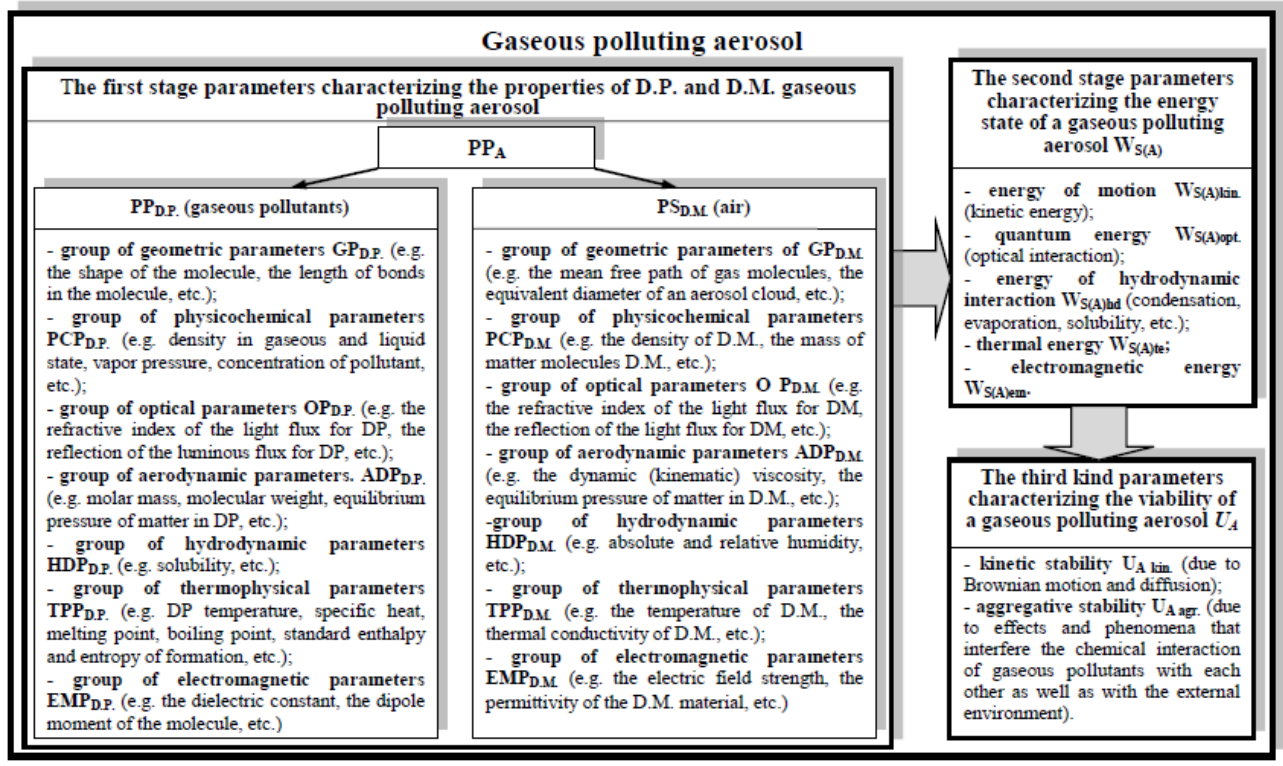

Fig. 2. Systematization of parameters that determine behavior of gaseous polluting aerosols from the perspective of the disperse systems theory.

2-nd group - parameters of the second kind - energy pollutant parameters $\mathrm{W}_{\mathrm{S}(\mathrm{A})}$, which characterize the acquisition, distribution and energy consumption of aerosol and are determined by the interconnected complex of groups of $\mathrm{PP}_{\mathrm{A}}$ aerosol properties parameters;

3-d group - parameters of the third kind - aerosol stability $U_{A}$ - resultant characteristic, which is the ability of the pollutant to resist external influences (its viability), which determines the features of its behavior and is a characteristic of the intensity of changes in $\mathrm{PP}_{\mathrm{A}}$ and $\mathrm{W}_{\mathrm{S}(\mathrm{A})}$ disperse systems for a certain time interval under external conditions effects.

The consideration of gaseous pollutants as disperse systems within the framework of the physical and energetic approach allows us to give their most complete characterization, to investigate processes and phenomena occurring in aerosols and to systematize the properties parameters by groups whose main classification feature is the physical essence of processes and phenomena occurring in aerosols [24]. Ultimately, this will allow controlling the stability and therefore the behavior of such aerosols and will provide an opportunity to reduce air pollution.

To reduce pollution by power plants in the air basin, air pollutants purification, which is the maximum separation of the D.P. and D.M. dispersed system is used. In the case when the implementation of the purification process does not allow to reach the concentration of pollutants in an ecologically significant zone, the corresponding maximum allowable concentration, the process of reducing air pollution provides the additional realization of the forced dispersion of pollutants, which means the intensive decontamination of pollutants during their release into the atmosphere. During the process of pollutants scattering an additional decrease in the concentration of pollutants in the surface layer of the atmosphere is achieved to the level of maximum allowable concentration [25].

The purpose of the process of reducing air pollution is to change the stability of the polluting aerosol in accordance with the presented scheme of disperse systems transformation (Fig. 3) and ultimately its destruction due to the separation of the D.P. and D.M. At the same time when additional dispersed systems are exposed to a gaseous polluting aerosol, transitions from one state of the disperse system to another (starting 
material $\rightarrow$ pollutant material $\leftrightarrow$ gaseous polluting aerosol) are performed with a change in the polluting aerosol stability.

\begin{tabular}{|c|c|c|c|c|}
\hline \multirow{2}{*}{ 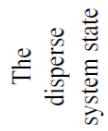 } & \multirow{2}{*}{ 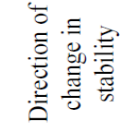 } & \multicolumn{3}{|c|}{$\begin{array}{l}\text { The contamination of air pollution reducing process } \\
\text { II cycle: reduction of air pollution basin }\end{array}$} \\
\hline & & air pollutan & purification & ispersion \\
\hline 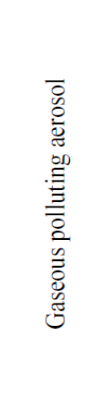 & $\begin{array}{c}\text { Steady } \\
\text { state } \\
\mathrm{dU}_{\mathrm{A}} / \mathrm{d} \tau>0 \\
\\
\\
\\
\\
\\
\mathrm{dU}_{\mathrm{A}} / \mathrm{d} \tau<0 \\
\text { Unstable } \\
\text { state }\end{array}$ & $\begin{array}{c}\text { «Supplementary- } \\
\text { II.2» («S-II.2») } \\
\text { (air } \\
\text { purification } \\
\text { from gaseous } \\
\text { substances) }\end{array}$ & $\begin{array}{l}\text { «Supplementary- } \\
\text { II.3» («S-II.3») } \\
\text { (forced } \\
\text { dispersion of } \\
\text { pollutants) } \\
\text { «I.1» («I-II.1») } \\
\text { (sent for } \\
\text { dispersion) }\end{array}$ & 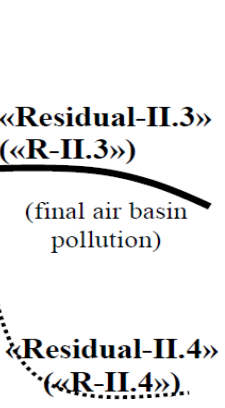 \\
\hline 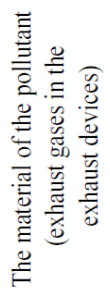 & $\begin{array}{c}\text { Unstable } \\
\text { state } \\
\mathrm{dU}_{\mathrm{A}} / \mathrm{d} \tau<0 \\
\\
\\
\mathrm{dU}_{\mathrm{A}} / \mathrm{d} \tau>0 \\
\text { Steady } \\
\text { state }\end{array}$ & & $\begin{array}{l}\text { Residual-II.2» } \\
(\text { («-II.2») } \\
\begin{array}{c}\text { Space (channel, flue) } \\
\text { for gaseous }\end{array} \\
\text { substances collection }\end{array}$ & $\begin{array}{l}\text { (in the ground } \\
\text { layer } \\
\text { atmosphere) }\end{array}$ \\
\hline 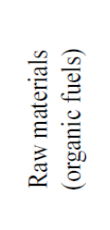 & $\begin{array}{c}\text { Unstable } \\
\text { state } \\
\mathrm{dU}_{\mathrm{A}} / \mathrm{d} \tau<0 \\
\mathrm{dU}_{\mathrm{A}} / \mathrm{d} \tau>0 \\
\text { Steady } \\
\text { state }\end{array}$ & $\begin{array}{c}\mid \begin{array}{c}\text { «nitial-I } \\
(\ll \mathbf{I}-\mathbf{I} »)\end{array} \\
\begin{array}{c}\text { The combustion zone } \\
\text { (combustion chamber, } \\
\text { boiler furnace) }\end{array}\end{array}$ & & \\
\hline
\end{tabular}

Fig. 3. Scheme of gaseous pollutants transformation in the process of reducing air pollution for power plants.

So the gaseous pollutants formed in the combustion of fuel act with the pre-prepared «Supplementary-II.1» («S-II.1») disperse system during the purification process. In this case, two disperse systems are formed [25]:

$1-$ «Intermediate-II.1» («I-II.1») dispersed system which is a polluting aerosol with a certain residual concentration of pollutants, sent either to the atmosphere (if the maximum permissible emissions are met) or to the zone of the forced dispersion. In this case, «I-II.1» disperse system is characterized by an increased value of stability as an aerosol.

2 - «Residual-II.2» («R-II.2») dispersed system, which is characterized by an increased content of gaseous pollutants and reduced stability. «R-II.2» disperse system is sent to the utilization system.

In the process of forced dispersion on the «I-II.1» disperse system purposefully influence the «Supplementary-II.3» disperse system, prepared in advance according to the given parameters. As a result, two disperse systems are formed in the aerosol state:

$1-\langle$ Residual-II.3» («R-II.3») dispersed system, represented by the maximum number of particles of pollutants. After interacting with the «S-II.3» disperse system, it reduces its stability as a polluting aerosol and forms the final contamination of the air basin.

2 - «Residual-II.4» («R-II.4») dispersed system, is represented by a minimal amount of pollutants; it remains in the aerosol state, its stability decreases with time and then is 
stabilized. This system forms the residual concentration of pollutants in the air basin of the territory under consideration.

It is also important at the design stage to make the right choice of the structural elements and performance characteristics of the process and the system for reducing air pollution. This will ensure maximum environmental efficiency and energy efficiency of the process.

\section{Conclusions}

Thus, as a result of our studies we have systematized the parameters of properties, energy parameters and stability of gaseous pollutants formed during the operation of power plants. The scheme developed for the transformation of gaseous pollutants in the process of reducing air pollution for power plants allows:

- to identify possible types of exposure to gaseous pollutants in order to reduce air pollution;

- to control the behavior of gaseous pollutants in order to reduce their stability and, ultimately, to reduce air pollution on the basis of the analysis of changes directions in the stability of various states of disperse systems.

In previous works [26] a mathematical description of the optimization criteria for the hydrodynamic method of purification from gaseous pollutants performed by us has been presented. The next stage of our research will be the study of the physical features of the process of forced dispersion, the properties of gaseous pollutants not detained by the cleaning element, the properties of the surrounding air environment as well as the derivation of parametric dependences of the environmental efficiency and energyconsuming parameter of the forced dispersion process as the resulting parameters for operating conditions of power plants.

\section{References}

1. P. Rayst, Aerosols - an introduction to the theory (Moscow, Mir, 1987)

2. H. Greene, W. Lane, Aerosols - dust, fumes and mists (Leningrad, Himiya, 1972)

3. S. Bretschneider, The Properties of Gases and Liquids, (Leningrad, Himiya, 1966)

4. P. A. Kouzov, L. Ya. Skryabina, Methods for determination of physical and chemical properties of industrial dusts (Leningrad, Himiya, 1983).

5. N. A. Fuchs, The mechanics of aerosols (Moscow, Academy of Sciences Publishing House, 1955)

6. V. I. Bespalov, L. Z. Ganicheva, N. V. Yudina, O. N. Paramonova, T. L. Pirozhnikova, I. N. Gevorkyants, BBRA, 11, 27-35 (2014)

7. E. P. Lysova, O. N. Paramonova, International scientific-practical conference «Theoretical, methodological and applied aspects of science», 34-36, 2014

8. L. Z. Ganicheva, N. V. Yudina, E. P. Lysova, T. L. Pirozhnikova, I. N. Gevorkyants, Scientific review, 7 (3), 767-769 (2014)

9. E. P. Lysova, International scientific-practical conference «Current state and prospects of technical sciences development», 79-81 (2015)

10. I. A. Ilchenko, News of Higher Educational Institutions. The North Caucasus region. Series: Natural sciences, 6, 79-83 (2009)

11. V. R. Kotler, S. E. Belikov, Industrial heating plants: combustion of fuels and protection of the atmosphere (St Petersburg, Energotech, 2001) 
12. V. Ya. Putilov, Ecology of Power Engineering (Moscow, MEI, 2003)

13. I. H. Choi, W. K. Jo, AAQR, 11, 412-418 (2011)

14. S. Paliwal, H. Chandra, A. Tripathi, IJMET, 4, 2-37 (2013)

15. V. I. Bespalov E. P. Lysova, Collection of scientific works SWorld, 2 (1), 19-24 (2015)

16. E. Yu. Bezuglaya, I. V. Smirnova, Air of cities and its changes (St Petersburg, Asteron, 2008)

17. M. E. Berlyand, Forecast and regulation of air pollution (Leningrad, Gidrometeoizdat, 1985)

18. N. A. Strakhova, L. Yu. Ovchinnikova, A. B. Pleskachev, Technical solutions on protection of air environment against the polluting substances (Rostov-on-Don, Rostov State Civil Engineering University, 2002)

19. Method of calculating the concentrations of harmful substances contained in the emissions of enterprises (Leningrad, Gidrometeoizdat, 1987)

20. V. V. Pinigin, Improvement the forecasting harmful emissions quality from boiler installations of thermal power plants (Chita, Transbaikal State University, 2014)

21. V. M. Brodyansky, V. Fratscher, K. Mikhalek. The exergy method and its applications (Moscow, Energoatomizdat, 1988)

22. V. I. Bespalov, News of the North Caucasian Scientific Center of Higher School. Natural Sciences, 9, 37-47 (1995)

23. E. P. Lysova, L. A. Lisutina, All-Russia Scientific and Practical Conference «Lowwaste, resource-saving chemical technologies and environmental safety», 192-193 (2013)

24. L. Z. Ganicheva, O. N. Paramonova, N. V. Yudina, E. P. Lysova, Scientific review, 9 (3), 917-919 (2014)

25. E. Lysova, O. Paramonova, O. Gurova. MATEC Web of Conferences (ICMTMTE 2017) 129, 05016 (2017)

26. V. I. Bespalov, O. S. Gurova, O. N. Paramonova, E. P. Lysova, BBRA, 12(2), 1459$1470(2015)$ 